\title{
PERAN JOB EMBEDDEDNESS TERHADAP KINERJA DENGAN KETERIKATAN KERJA DAN KEINGINAN UNTUK MENETAP SEBAGAI MEDIATOR
}

\author{
Elvina Pekasa ${ }^{1}$ dan Rostiana ${ }^{2}$ \\ ${ }^{1}$ Fakultas Psikologi, Universitas Tarumanagara \\ Email: tugas.vina@gmail.com \\ ${ }^{2}$ Fakultas Psikologi, Universitas Tarumanagara \\ Email: rostiana@fpsi.untar.ac.id
}

\begin{abstract}
ABSTRAK
Kinerja adalah salah satu hal kunci yang harus diperhatikan oleh semua perusahaan. Banyak variabel yang sudah terbukti dapat memprediksi kinerja, namun penelitian selama satu dekade terakhir ini mulai mengembangkan sebuah konsep baru yaitu job embeddedness. Job embeddedness diasumsikan berhubungan dengan kinerja melalui keterikatan kerja dan intention to stay akan tetapi belum ada penelitian yang membuktikan hal ini. Penelitian ini dilakukan di PT X, sebagai salah satu perusahaan manufaktur otomotif terbesar di Indonesia. Jumlah sampel yang digunakan sejumlah 305 orang. Metode analisis dilakukan dengan regresi ganda. Dari hasil analisis data ditemukan bahwa peran job embeddedness terhadap kinerja dimediasi secara parsial oleh keterikatan kerja dan keinginan untuk menetap.
\end{abstract}

Kata kunci: kinerja, job embeddedness, keterikatan kerja, keinginan untuk menetap

\section{PENDAHULUAN}

Pada abad ke 21, globalisasi telah memaksa perekonomian untuk berubah ke arah pelayanan dan pengembangan teknologi tidak terkecuali untuk industri otomotif. Cepatnya pertumbuhan industri otomotif global membuat para produsen besar bersaing ketat untuk mendapatkan pangsa pasar (Kementrian Perdagangan Republik Indonesia, 2014). Dengan pesatnya perkembangan industri ini, perusahaan dituntut untuk mengikuti dan menyesuaikan diri dengan cepat, tidak terkecuali untuk PT X. PT X adalah salah satu perusahaan manufaktur filter terbesar di Indonesia yang sudah mengekspor barangnya ke lebih dari 115 negara di dunia. Berdasarkan annual report pada tahun 2016, PT X berhasil mempertahankan pertumbuhan penjualan tanpa terputus selama 24 tahun dan 17 tahun pertumbuhan penjualan ekspor tanpa terputus. Namun jika diperhatikan, pertumbuhan penjualan ini mengalami penurunan di mana pada pada tahun 2014-2015 sebesar 6,45\% menjadi hanya 2,75\% di tahun 2015-2016.

Pertumbuhan penjualan ini merupakan salah satu indikator utama dari performa atau kinerja perusahaan. Kinerja perusahaan tidak pernah terlepas dari kinerja individunya, di mana kinerja individu di PT X juga tidak banyak mengalami peningkatan sejak tahun 2015. Berdasarkan data terbaru, kinerja karyawan justru cenderung mengalami penurunan di semester pertama tahun ini. Menurunnya kinerja ini menjadi fenomena penting yang harus diperhatikan oleh PT X.

\section{Job embeddedness dan kinerja}

Terdapat banyak hal yang sudah terbukti dapat memengaruhi kinerja individu namun selama satu dekade terakhir ini, berkembang sebuah konsep baru yang diprediksi sebagai salah satu prediktor dari kinerja yaitu job embeddedness (Lee, Mitchell, Sabliyanski, Buton \& Holtom, 2004; Halbesleben \& Wheeler, 2008; Sekiguchi, Burton \& Sabliyanski, 2008; Wheeler, Harris \& Sabliyanski, 2012). Dari hasil penelitian tersebut, ditemukan bahwa job embeddedness berhubungan dengan kinerja, baik secara langsung maupun tidak langsung. 
Job embeddedness dapat diartikan sebagai perpaduan kekuatan atau faktor-faktor yang membuat seseorang bertahan untuk tidak meninggalkan pekerjaannya (Mitchell, Holtom, Lee, Sablynski \& Erez, 2001). Job embeddedness ini terdiri dari tiga komponen yaitu fit, links dan sacrifices (Mitchell et al., 2001). Job embeddedness awalnya dikembangkan oleh Mitchell, et al. (2001) untuk menjawab hal-hal apa saja yang membuat karyawan tetap tinggal di dalam perusahaan (keinginan untuk menetap). Namun peneliti selanjutnya seperti Lee, Mitchell, Sabliyanski, Burton \& Holtom (2004); Sekiguchi, Burton dan Sabliyanski (2008); dan Wheeler, Harris dan Sabliyanski (2012) mulai mengembangkan peran job embeddedness terhadap outcomes perusahaan seperti kinerja. Meskipun secara teoretik peran job embeddedness terhadap kinerja sudah diungkapkan, namun Lee, Burch \& Mitchell (2014) meragukan bahwa dasar teori yang menjelaskan bagaimana job embeddedness berpengaruh terhadap kinerja sudah kuat, sehingga masih perlu diuji kembali. Oleh karena itu, peneliti ingin mengetahui variabel apa yang dapat berperan menjadi intervening variable untuk menjelaskan pengaruh job embeddedness terhadap kinerja.

\section{Job embeddedness, keterikatan kerja dan kinerja}

Kinerja sudah secara konsisten diprediksi oleh aspek motivasi, seperti keterikatan kerja di mana karyawan yang memiliki motivasi internal yang kuat akan terdorong untuk mencapai kinerja yang lebih tinggi (Bakker \& Demerouti, 2008; Halbesleben \& Wheeler, 2008; Bakker \& Bal, 2010; Bakker, Demerouti \& Brummelhuis, 2012; Takawira, Coetzee \& Schreuder, 2014). Keterikatan kerja atau work engagement dapat diartikan sebagai kondisi psikologis yang bersifat positif dan berhubungan dengan pekerjaan yang dikarakteristikan melalui vigor, dedication dan absorption (Schaufeli, Salanova, Gonzales-Roma \& Bakker, 2002).

Ketiga dimensi keterikatan kerja ini berhubungan dengan job embeddedness, di mana karyawan yang merasa organisasi dan pekerjaannya sejalan dengan aspek kehidupannya (seperti value pribadi, tujuan karir atau rencana masa depan) akan terdorong untuk memberikan usaha yang lebih, memiliki rasa keterlibatan yang kuat dan sulit untuk memisahkan diri dari pekerjaannya. Lee, et al. (2004) mengasumsikan bahwa ketiga dimensi job embeddedness yaitu fit, links dan sacrifices memiliki hubungan yang positif dengan kinerja melalui aspek motivasi. Akan tetapi peran keterikatan kerja sebagai mediator antara job embeddedness dan kinerja masih perlu diteliti karena masih terbatasnya penelitian yang menggunakan keterikatan kerja sebagai mediator untuk menjelaskan peran job embeddedness terhadap kinerja. Oleh karena itu peneliti ingin mengetahui apakah keterikatan kerja dapat menjadi mediator peran job embeddedness terhadap kinerja.

\section{Job embeddedness, keinginan untuk menetap dan kinerja}

Fenomena lain yang perlu diperhatikan oleh PT X selain kinerja adalah rendahnya tingkat turnover $(<1 \%)$. Meskipun pada tahun 2015 - 2016 kinerja dan pertumbuhan penjualan menurun, namun perusahaan tetap mampu mempertahankan persentase turnover karyawannya di bawah $1 \%$. Rendahnya persentase turnover ini mengasumsikan bahwa ternyata masih banyak karyawan yang tetap ingin tinggal di dalam perusahaan di mana hal ini dapat menjadi salah satu keuntungan perusahaan untuk meningkatkan kinerjanya (Park \& Shaw, 2013; Hom, Lee, Shaw \& Hausknecht, 2017).

Keinginan untuk menetap ini telah terbukti diprediksi oleh job embeddedness (Lee, et al., 2004; Mallol, Holtom \& Lee, 2007; Murphy, et al., 2013) dan diasumsikan dapat meningkatkan kinerja (Hunja, Raza \& Munir, 2014; Susanto \& Kurniawan, 2016). Penelitian Hunja, et al. (2014) menemukan bahwa keinginan untuk menetap dan produktivitas berhubungan secara signifikan dengan kinerja. Penelitian Susanto \& Kurniawan (2016) juga menemukan bahwa 
keinginan untuk menetap berhubungan dengan performa kerja. Meskipun secara konsep ketiga variabel ini berhubungan, masih sedikit penelitian yang melihat hubungan ketiga variabel ini, terutama yang menggunakan keinginan untuk menetap sebagai mediator. Oleh karena itu peneliti juga ingin mengetahui apakah keinginan untuk menetap dapat berperan sebagai mediator peran job embeddedness terhadap kinerja.

Berdasarkan penjelasan di atas peneliti tertarik untuk mengetahui apakah keterikatan kerja dan keinginan untuk menetap dapat memediasi peran job embeddedness terhadap kinerja. Selain itu, peneliti juga tertarik untuk mengetahui mediator mana yang berperan lebih besar dalam memediasi peran job embeddedness terhadap kinerja.

\section{METODE PENELITIAN}

Penelitian ini merupakan penelitian kuantitatif dengan bentuk non-eksperimental untuk melihat apakah keterikatan kerja dan keinginan untuk menetap dapat berperan sebagai mediator antara job embeddedness dan kinerja. Jumlah partisipan pada penelitian ini adalah 305 orang. Adapun teknik sampling yang digunakan adalah metode probability sampling dengan teknik cluster sampling. Penentuan sampel didasarkan pada pertimbangan peneliti dengan melihat kesesuaian pada karakteristik partisipan yang dibutuhkan oleh peneliti untuk melakukan pengambilan data dengan situasi di lapangan..

Pengukuran variabel job embeddedness menggunakan kuesioner adaptasi dari Mitchell, et al. (2001). Variabel ini terdiri dari sembilan butir positif dengan koefisien alpha cronbach dari hasil tryout sebesar 0.76. Sedangkan untuk variabel keterikatan kerja menggunakan adaptasi kuesioner Uthrect Work Engagement Scale (UWES-9) dari Schaufeli \& Bakker (2004). Kuesioner ini terdiri dari sembilan butir positif dan melalui hasil uji reliabilitas, diketahui bahwa keterikatan kerja memiliki koefisien alpha cronbach dari hasil tryout sebesar 0.83 .

Pengukuran variabel keinginan untuk menetap menggunakan tiga item yang dikembangkan oleh Armstrong-Stassen dan Ursell (2009) dan tiga item yang dikembangkan oleh peneliti dengan tujuan untuk melihat intensi secara keseluruhan. Variabel ini memiliki lima butir positif dan satu butir negatif dengan koefisien alpha cronbach dari hasil tryout sebesar 0.88 . Sedangkan untuk pengukuran variabel kinerja menggunakan kuesioner Individual Work Performance yang dikembangkan oleh Koopmans, Bernaards, Hildebrant, Van der Beek \& de Vet (2014). Kuesioner ini terdiri dari tiga puluh tujuh butir positif dan sepuluh butir negatif dengan koefisien alpha cronbach dari hasil tryout sebesar 0.93 .

\section{HASIL DAN PEMBAHASAN}

Analisis data pada penelitian ini dilakukan secara bertahap dengan melakukan uji regresi ganda menggunakan program SPSS. Pengujian efek mediator dilakukan dengan menggunakan metode Monte Carlo. Dengan menggunakan metode regresi linear, dari tahap pertama diperoleh $\beta=0.58, \mathrm{R}^{2}=0.23$ dengan tingkat signifikansi sebesar $\mathrm{P} \leq 0.01$. Artinya, variabel job embeddedness berkorelasi kinerja secara signifikan. Dari hasil tahap kedua, diperoleh nilai $\beta=$ $0.86, \mathrm{R}^{2}=0.28$ dengan tingkat signifikansi $\mathrm{P}<0.01$. Artinya, terdapat korelasi yang signifikan antara job embeddedness dengan keterikatan kerja.

Dari tahap ketiga (b), diperoleh nilai antara keterikatan kerja dengan kinerja sebesar $\beta=0.38$, $\mathrm{R}^{2}=0.33$ dengan tingkat signifikansi $\mathrm{P}<0.01$. Artinya, keterikatan kerja korelasi secara signifikan dengan kinerja. Pada tahap keempat ( $\left.c^{\prime}\right)$, diperoleh nilai sebesar $\beta=0.27, R^{2}=0.37$ 
dengan tingkat signifikansi $\mathrm{P}<0.01$. Hal ini berarti peran job embeddedness terhadap kinerja dimediasi oleh keterikatan kerja secara parsial, karena hasil dari tahap keempat signifikan dan nilai $\beta>0$. Selain itu nilai $\mathrm{R}^{2}$ dari regresi job embeddedness dan keterikatan kerja terhadap kinerja (c') lebih besar daripada $\mathrm{R}^{2}$ dari regresi job embeddedness ke kinerja (c).

Setelah mengetahui keterikatan kerja dapat menjadi mediator parsial. Maka penelitian dilanjutkan untuk menguji efek keterikatan kerja sebagai mediator. Uji efek mediator ini dilakukan dengan metode Monte Carlo. Dari hasil analisis menunjukkan bahwa distribusi interval efek tidak langsung (indirect effect) tidak sama dengan 0 pada $95 \%$ confidence interval $(\mathrm{LL}=0.18, \mathrm{UL}=0.34)$ hal ini berarti efek keterikatan kerja sebagai mediator tergolong signifikan. Dengan demikian keterikatan kerja dapat memediasi peran job embeddedness terhadap kinerja karyawan di PT X.

Prosedur analisis data untuk uji hipotesis kedua dilakukan dengan cara yang sama dengan uji hipotesis pertama. Dengan menggunakan metode regresi linear, dari hasil tahap pertama, diperoleh nilai $\beta=0.58, \mathrm{R}^{2}=0.23$ dengan tingkat signifikansi sebesar $\mathrm{P} \leq 0.01$. Artinya, variabel job embeddedness berkorelasi kinerja secara signifikan. Dari hasil tahap kedua (a), diperoleh nilai $\beta=0.90, \mathrm{R}^{2}=0.39$ dengan tingkat signifikansi $\mathrm{P}<0.01$. Artinya, terdapat korelasi yang signifikan antara job embeddedness dengan keinginan untuk menetap. Dari tahap ketiga (b), diperoleh nilai antara keinginan untuk menetap dengan kinerja sebesar $\beta=0.17, \mathrm{R}^{2}$ $=0.20$ dengan tingkat signifikansi $\mathrm{P}<0.01$. Artinya, keinginan untuk menetap berkorelasi secara signifikan dengan kinerja.

Pada tahap keempat (c'), diperoleh nilai sebesar $\beta=0.36, \mathrm{R}^{2}=0.26$, dengan tingkat signifikansi $\mathrm{P}<0.01$. Hal ini berarti peran job embeddedness terhadap kinerja dimediasi oleh keinginan untuk menetap secara parsial, karena hasil dari tahap keempat signifikan dan nilai $\beta>0$. Selain itu nilai $\mathrm{R}^{2}$ dari regresi job embeddedness dan keinginan untuk menetap terhadap kinerja (c') lebih besar daripada $\mathrm{R}^{2}$ dari regresi job embeddedness ke kinerja (c).

Setelah mengetahui keinginan untuk menetap dapat menjadi mediator parsial. Maka penelitian dilanjutkan untuk menguji efek keinginan untuk menetap sebagai mediator. Uji efek mediator ini dilakukan dengan metode Monte Carlo. Dari hasil analisis menunjukkan bahwa distribusi interval efek tidak langsung (indirect effect) tidak sama dengan 0 pada $95 \%$ confidence interval $(\mathrm{LL}=0.06, \mathrm{UL}=0.24)$ hal ini berarti efek keinginan untuk menetap sebagai mediator tergolong signifikan. Dengan demikian, keinginan untuk menetap dapat memediasi peran job embeddedness terhadap kinerja karyawan di PT X.

Berdasarkan analisis di atas terlihat bahwa keterikatan kerja dan keinginan untuk menetap dapat berperan sebagai mediator parsial. Untuk menguji hipotesis ketiga, dilakukan perbandingan nilai $\mathrm{R}^{2}$. Dari hasil perbandingan, keterikatan kerja memiliki nilai yang lebih besar sebagai mediator $\left(\mathrm{R}^{2}=0.37\right)$ antara job embeddedness dan kinerja dibandingkan dengan keinginan untuk menetap $\left(\mathrm{R}^{2}=0.26\right)$. Oleh karena itu keterikatan kerja berperan lebih besar daripada keinginan untuk menetap sebagai mediator peran job embeddedness terhadap kinerja. 


\section{SIMPULAN, DISKUSI DAN SARAN \\ Simpulan dan diskusi}

Berdasarkan hasil analisis dapat disimpulkan bahwa job embeddedness dapat berperan secara langsung maupun tidak langsung yaitu melalui keterikatan kerja dan keinginan untuk menetap. Keterikatan kerja juga ditemukan memiliki peran yang lebih besar dibandingkan keinginan untuk menetap sebagai mediator peran job embeddedness terhadap kinerja. Dari hasil uji hipotesis pertama, ditemukan bahwa keterikatan kerja dapat berperan sebagai mediator antara job embeddedness dengan kinerja. Hal ini mendukung pernyataan Lee, et al. (2004) yang mengasumsikan bahwa job embeddedness memiliki hubungan yang positif dengan kinerja melalui aspek motivasi. Dari hasil uji hipotesis kedua, ditemukan bahwa keinginan untuk menetap dapat berperan sebagai mediator antara job embeddedness dengan kinerja. Hal ini mendukung penelitian Mitchell, et al. (2001), Holtom, Mitchell, Lee dan Eberly (2008), Murphy, et al. (2013) yang mengungkapkan bahwa job embeddedness akan mendorong seseorang untuk tetap tinggal di dalam perusahaan yang kemudian akan meningkatkan kinerja.

Dari penelitian lebih lanjut, keterikatan kerja ditemukan memiliki peran mediator yang lebih besar daripada keinginan untuk menetap. Hal ini dapat disebabkan oleh kesamaan konteks antara job embeddedness, kinerja dan keterikatan kerja, yaitu pekerjaan. Sedangkan keinginan untuk menetap tidak secara langsung berhubungan dengan pekerjaan namun lebih terkait dengan sosial atau lingkungan. Hubungan langsung dengan pekerjaan inilah yang dapat membuat keterikatan kerja berperan lebih besar dibanding keinginan untuk menetap.

\section{Saran}

Dari hasil penelitian di atas, untuk penelitian selanjutnya disarankan untuk meneliti lebih mendalam mengenai hubungan antara kedua mediator, yaitu keterikatan kerja dan keinginan untuk menetap. Diasumsikan bahwa kedua mediator ini saling berhubungan dan keterikatan kerja akan mendorong seseorang untuk tetap tinggal di dalam perusahaan. Disarankan juga untuk menggunakan self-assessment dan supervisor rating dalam pengukuran kinerja agar gambaran mengenai kinerja menjadi lebih objektif.

Bagi karyawan yang sudah bekerja di dalam perusahaan, disarankan agar perusahaan menjelaskan kepada karyawan mengenai rencana pengembangan karirnya di masa depan dan menyediakan kesempatan untuk belajar dan pengembangan diri agar dapat memenuhi rencana tersebut. Perusahaan juga dapat membuat insentif berdasarkan masa kerja dan jaminan pensiun yang baik agar karyawan mendapatkan rasa aman untuk terus bekerja di dalam perusahaan.

\section{Ucapan Terima Kasih (Acknowledgement)}

Peneliti mengucapkan terima kasih kepada pihak manajemen PT. X yang telah memberikan izin untuk mengambil data terkait penelitian ini. Selain itu, peneliti juga menghaturkan rasa terima kasih kepada seluruh partisipan yang sudah bersedia berpartisipasi dalam penelitian kali ini. 


\section{REFERENSI}

Bakker. A.B., \& Bal, P.M. (2010). Weekly work engagement and performance: a study among starting teachers. Journal of Occupational and Organizational Psychology, 83(3), 189 206.

Bakker. A.B., \& Demerouti, E. (2008). Towards a model of work engagement. Career Development International, 13(3), 209- 223.

Bakker. A.B., Demerouti, E., \& Brummelhuis, L.L.T (2012). Work engagement, performance, and active learning: The role of conscientiousness. Journal of Vocational Behavior, 80, $555-564$.

Halbesleben, J.R.B., \& Wheeler, A.R. (2008). The relative roles of engagement and embeddedness in predicting job performance and intention to leave. Work \& Stress, 22(3), $242-256$.

Hom, P.W., Lee, T.W., Shaw, J.D., \& Hausknecht, J.P. (2017). One hundred years of employee turnover theory and research. Journal of Applied Psychology, 102(3), 530 - 545.

Hunja, A.I., Raza, H., \& Munir, I.U. (2014). The role of employee retention and employee productivity on the performance of oil and gas sector of Pakistan. International Journal of Economics and Empirical Research, 2(11), 449 - 453.

Koopmans, L., Bernaards, C.M., Hildebrandt, V.H., Van der Beek, A.J., \& de Vet, C.H. (2014). Construct validty of the individual work performance questionnaire. American College of Occupational and Environmental Medicine, 56, 331 - 337.

Lee, T.W., Burch, T.C., \& Mitchell, T.R. (2014). The story wof why we stay: a review of job embeddedness. Annual Review of Organizational Psychology and Organizational Behavior, 199 - 216.

Lee, T.W., Mitchell, T.R., Sabliyanski, C.J., Burton, J.P., \& Holtom, B.C. (2004). The effect of job embeddedness on organizational citizenship, job performance, volitional absences, and voluntary turnover. The Academy of Management Journal, 47(5), 711 - 722.

Mallol, C.M., Holtom, B.C., \& Lee, T.W. (2007). Job embeddedness in a culturally diverse environment. Journal of Business Psychology, 22, 35 - 44.

Mitchell, T.R., Holtom, B.C., Lee, T.W., Sablynski, C.J., \& Erez, M. (2001). Why people stay: using job embeddednes to predict voluntary turnvoer. Academy of Management Journal, 44(6), $1102-1121$.

Murphy, W.M., Burton, J.P., Henagan, S.C., \& Briscoe, J.P. (2013). Employee reactions to job insecurity in a declining economy. Journal of Group and Organization Management, $38(4), 512-537$.

Park, T.Y., \& Shaw, J.D. (2013). Turnover rates and organizational performance: a meta analysis. American Psychological Association, 98(2), 268 - 309.

Sekiguchi, T., Burton, J.P., \& Sabliyanski, C.J. (2008). The role of job embeddedness on employee performance: the interactive effects with leader member exchange and organization based self esteem. Personnel Psychology, 61, $761-792$.

Schaufeli, W.B., \& Bakker, A.B. (2004). Job demands, job resources, and their relationship with burnout and engagement: a multi-sample study. Journal of Organizational Behavior $24,293-315$.

Schaufeli, W.B., Salanova, M., Gonzales-Roma, V., \& Bakker, A.B. (2002).The measurement of engagement and burnout. Journal of Bridging Occupational, Organizational and Public Health, $43-68$.

Susanto, E.M., \& Kurniawan, M. (2016). The impact of recruitment, employee retention and labor relations to employee performance on batik industri in Solo city Indonesia. International Journal of Business and Society, 17(2), 375 - 390. 
Takawira, N., Coetzee, M., \& Schreuder, D. (2014). Job embeddedness, work engagement and turnover intention of staff in a higher education institution: an exploratory study. $S A$ Journal of Human Resource Management, 12(1), 1 - 10.

Wheeler, A.R., Harris, K.J., \& Sabliyanski, C.J. (2012). How do employees invest abundant resources? The mediating role of work effort in the job embeddedness/job performance relationship. Journal of Applied Social Psychology, 42(1), 244 - 266. 